\title{
Determination of Crop Phenological Phase Based on Leaf Number and Net Photosynthetic Rate in Six Maize (Zea mays L.) Hybrids
}

\author{
M. Ravi Babu*, K. L. Narasimharao, Y. Ashoka Rani, \\ M. Martinluther and P. R. K. Prasad \\ Department of Crop Physiology Agricultural college ANGRAU Bapatla 522101, India \\ *Corresponding author
}

A B S T R A C T

Keywords

Photosynthetic, reproductive growth, vegetative development

Article Info

Accepted:

25 August 2019

Available Online:

10 September 2019
A field experiment was conducted to study the determination of crop age based on leaf number and photosynthetic rate was under taken at the Agricultural College farm, Bapatla duringrabi 2016-17. The experiment was laid out in randomized block design with six maize hybrids as treatments in four replications. The stage at which the reproductive growth was attained in all maize hybrids, based on number of leaves expanded on the stem at 42DAS, vary among hybrids differently. Pinnacle (V12-12.50), DKC9142 (V12-12.25), DKC 9042 (V12-12.00), 900MGOLD (V11-11.75) and DKC 9081 (V11-11.50). The hybrids DKC 9142 (36.35) and Pinnacle (36.30) continued its dominance of significance in net photosynthetic rate till 63DAS. However, the maximum net photosynthetic rate was recorded among all maize hybrids during crop growth period at 70DAS ranged from 37.80 to 39.95 but all hybrids are at a par in $\mathrm{P}_{\mathrm{n}}$ values.

\section{Introduction}

Maize is the world's third most important cereal crop after wheat and rice. The maize production in India about 22 million tonnes with an area of 9.2 million hectare. Several experiments were conducted to determine the growth stages of maize in a given environment. But, the basis for the variation in dry matter production and reproductive growth in relation to its foliage is less understood. The leaf growth that designates the physiological age of crop is more useful for crop improvement programmes.

Leaf development, represented by the appearance and accumulation of leaves is an important part of the vegetative development of agricultural crops. In maize, leaf development starts at emergence and ends with the appearance and expansion of the flag leaf, when the final leaf number (FLN) is defined. In maize crop the vegetative development overlaps the reproductive one. 
Therefore, leaf number (LN) is related to some reproductive developmental stages, such as ears and tassel initiation (Forsthofer et al., 2004). As leaf number increases, crop leaf area index (LAI) for net photosynthesis and crop biomass production (dry matter) also increases. Application of nutrients in maize is also related to leaf number (LN), being recommended at V4 (four expanded leaves), V7 (seven expanded leaves), and V11 (eleven expanded leaves) (Forsthofer et al., 2004). Thus any management practice or biotic or abiotic stresses that effect the leaf development may potentially impact the reproductive growth and development and ultimately influence the crop yield.

Photosynthetic $\mathrm{CO}_{2}$ fixation by plants responds immediately to fluctuations in the density of the photosynthetic photon flux (Q), such that the gain of dry mass is closely related to the light utilization ability of plants. This ability, in turn, depends primarily on the leaf area index (LAI) and also the arrangement of leaves in the canopy, the morphology and anatomy of leaves, the sun elevation, changes in the quality or spectral distribution and the multiple reflection of $\mathrm{Q}$ within the canopy (Bavec and Bavec, 2002; Montpied et al., 2009; Nobel et al., 1993; Patakas et al., 2003; Stewart et al., 2003). According to Nobel et al., (1993), the flux density of photons reaching each level in the crop canopy is considered to be the main factor determining the rate of $\mathrm{CO}_{2}$ assimilation by individual leaves. It has been suggested that, to understand the contribution of each leaf individually for photosynthesis, the overall foliage canopy must be considered with regard to the variability of $\mathrm{Q}$ penetrating the vegetation layers. It is known that when $Q$ penetrates the canopy, it decreases approximately exponentially depending on the number of leaves (Hirose, 2005). Therefore, the overall photosynthesis of a plant community depends on both the $\mathrm{Q}$ absorbed by the leaf canopy and also on its distribution in the culture profile (Montpied et al., 2009; Nobel et al., 1993).

\section{Materials and Methods}

The field experiment was laid out in randomized block design with six maize hybrids i.e.900MGOLD, V2-DKC 9142, V3DKC 9120,V4 - DKC 9081, V5 - DKC9042 and V6 - Pinnacle treatments in four replications at Agricultural College Farm, Bapatla during rabi season of 2016-2017.The details of material used and the methodologies followed during the course of investigation are presented here. Total number of leaves per plant was determined by tagging the $5^{\text {th }}$ leaf of five plants per plot at 14 DAS before the germination leaves senesced. When senescence had progressed, the tagged were adjusted to10th leaf. Total number of leaves were counted from 7DAS to anthesis while number of green leaves were counted up to physiological maturity. The number of leaves are counted based on the physical appearance and leaf tip emergence of the plant at every day observation for counting the leaf number index in relation to the age of the plant.

Leaf appearance rate was calculated on leaf tip (LN Tip) and on expanded leaf (LN expn) basis. A leaf was assumed expanded when ligule is visible.

The accumulated leaf number (LN) was calculated starting at crop emergence by calculating LAR was calculated as per Strek et al., 2009 presented in the following.

\section{$\boldsymbol{L N}=\Sigma \boldsymbol{L} A \boldsymbol{R}$}

Five plants were randomly selected and tagged in each plot after leaving boarder rows on all sides. The photosynthetic rate was recorded in the top most fully expanded leaf in the stem of the tagged plant at every seven days interval in all the treatments. 
Net photosynthetic rate was recorded between 10.00 AM to 12.00 noon using Infrared Gas Analyzer (TPS-2,PP systems),equipped with broad leaf cuvette (with $18 \mathrm{~mm} \varnothing$ chamber), under natural sun light, carbon dioxide and water vapour levels duly following the manufacturer's instructions of operations.

The data were analyzed by following the analysis of variance (ANOVA) technique as suggested by Panse and Sukhatme (1978). The statistical hypothesis of equalities of treatment means was tested by the test in ANOVA at 5 percent level of significance to compare different treatment means.

\section{Results and Discussion}

Maize is an economically important crop because of its widespread commercial production and utilization. It is well known that nutrient deficiency in most cultivated crops during the growth season causes imbalance, leading to low productivity and reduction in yield. Nutrient supply in critical stage of the crop, especially during the phase shift from vegetative phase to reproductive stage determines the crop productivity.

Hence the experiments were designed with maize hybrids to measure the requirement of growing degree days phase or stage wise during the crop growth and to fix a particular stage or age based on the leaf number index as a ready reckoner to identify the reproductive tissue differentiation for nutrient supply and to understand the pattern of assimilate partitioning during the crop growth.

\section{Number of Leaves plant ${ }^{-1}$}

The number of leaves in all hybrids from sowing to harvest increased from 3 to 16 (Table 1). During rabi 2016-17, among the hybrids at 7DAS Pinnacle and DKC 9142 significantly recorded the highest leaf number compared to DKC 9120, 900M Gold, which recorded the lowest and on par with DKC 9120 and 900M Gold. At 14 DAS, 900M Gold had the leaf number lower than other five hybrids which were found on par with leaf number ranging from 5.0 to 5.5. At 21 and 28 DAS DKC 9142, Pinnacle and DKC 9120 had the leaf number significantly higher than DKC 9081, 900M Gold and DKC 9042. At 35 DAS, leaf number was significantly less in DKC 9081 and DKC 9042 than other four hybrids which were found on par with leaf number ranging from 10.8 to 11.5 . At 42DAS, Pinnacle recorded significantly more number of leaves than DKC 9081, which had the less and on par with DKC 9142, DKC 9042, DKC 9120 and $900 \mathrm{M}$ Gold, that in turn were also showed parity with DKC 9081. At 49 DAS, Pinnacle and DKC 9142 had the leaf number greater than DKC9042,900M Gold and on par with DKC 9120,DKC 9081 which shoed parity also with DKC 9042 and 900M Gold. At 56 DAS, Pinnacle had more leaf number, significantly greater than DKC 9081, DKC 9120 and on par with DKC 9081.

Later 63DAS, Pinnacle DKC 9142 and 900M Gold had significantly more leaf number than DKC 9081 and these four hybrids were found on par DKC 9042 and DKC 9120. Finally at 70DAS to harvest, leaf number was significantly high in pinnacle, DKC 9142 and 900M Gold compared to other three hybrids.

In maize, leaf development starts at emergence and ends with an appearance and expansion of final leaf number which is defined for all maize hybrids i.e; from the date of seedling emergence to 70DAS.

In maize crop, vegetative development overlaps the reproductive stage, therefore leaf number is related to some reproductive developmental stages, such as tassel and ear initiation (Forsthofer et al., 2004). 
Table.1 Number of leaves in maize hybrids duringrabi2016-17

\begin{tabular}{|c|c|c|c|c|c|c|c|c|c|c|c|c|c|c|}
\hline Hybrids & 7 DAS & 14 DAS & 21 DAS & 28 DAS & 35 DAS & 42 DAS & 49 DAS & 56 DAS & 63 DAS & 70 DAS & 77 DAS & 84 DAS & 91 DAS & Harvest \\
\hline 900MGold (V1) & 3.0 & 4.2 & 6.2 & 8.8 & 10.8 & 11.8 & 13.0 & 14.3 & 14.8 & 15.8 & 15.8 & 15.8 & 15.8 & 15.8 \\
\hline DKC 9142 (V2) & 3.8 & 5.5 & 7.1 & 10.2 & 11.5 & 12.3 & 13.8 & 14.5 & 15.0 & 16.0 & 16.0 & 16.0 & 16.0 & 16.0 \\
\hline DKC 9120 (V3) & 3.0 & 5.2 & 6.6 & 10.0 & 10.8 & 11.8 & 13.3 & 14.0 & 14.5 & 15.5 & 15.5 & 15.5 & 15.5 & 15.5 \\
\hline DKC 9081 (V4) & 3.5 & 5.0 & 6.0 & 9.0 & 9.8 & 11.5 & 13.3 & 13.8 & 14.0 & 15.0 & 15.0 & 15.0 & 15.0 & 15.0 \\
\hline DKC 9042 (V5) & 3.5 & 5.0 & 6.5 & 9.0 & 10.0 & 12.0 & 13.0 & 14.3 & 14.5 & 15.0 & 15.0 & 15.0 & 15.0 & 15.0 \\
\hline Pinnacle (V6) & 4.0 & 5.5 & 7.0 & 10.0 & 10.8 & 12.5 & 13.8 & 14.8 & 15.0 & 16.0 & 16.0 & 16.0 & 16.0 & 16.0 \\
\hline SEm \pm & 0.29 & 0.29 & 0.26 & 0.19 & 0.35 & 0.43 & 0.29 & 0.35 & 0.34 & 0.23 & 0.23 & 0.232 & 0.232 & 0.232 \\
\hline CV\% & 12.09 & 6.73 & 5.18 & 2.93 & 4.77 & 5.19 & 3.16 & 3.54 & 3.36 & 2.11 & 2.11 & 2.11 & 2.11 & 2.11 \\
\hline$C D(p=0.05)$ & 0.63 & NS & 0.57 & 0.42 & 0.76 & 0.93 & 0.63 & 0.76 & 0.74 & 0.49 & 0.49 & 0.49 & 0.49 & 0.49 \\
\hline
\end{tabular}

Table.2 Net photosynthetic rate of maize hybrids duringrabi 2016-17

\begin{tabular}{|c|c|c|c|c|c|c|c|c|c|c|c|c|c|c|}
\hline Hybrids & 7 DAS & 14 DAS & 21 DAS & 28 DAS & 35 DAS & 42 DAS & 49 DAS & 56 DAS & 63 DAS & 70 DAS & 77 DAS & 84 DAS & 91 DAS & Harvest \\
\hline 900MGold (V1) & 5.5 & 7.7 & 11.3 & 22.0 & 30.8 & 33.5 & 34.5 & 35.9 & 37.4 & 39.3 & 36.7 & 31.9 & 22.0 & 18.9 \\
\hline DKC 9142 (V2) & 7.1 & 8.1 & 11.7 & 22.1 & 32.5 & 34.6 & 35.3 & 36.4 & 38.3 & 39.5 & 37.4 & 33.5 & 23.0 & 19.1 \\
\hline DKC 9120 (V3) & 6.0 & 7.5 & 11.4 & 21.2 & 31.2 & 32.0 & 34.8 & 35.6 & 37.1 & 38.6 & 36.7 & 31.3 & 21.8 & 18.8 \\
\hline DKC 9081 (V4) & 5.9 & 7.4 & 11.5 & 20.5 & 30.3 & 31.0 & 34.5 & 35.5 & 37.2 & 38.7 & 36.5 & 31.8 & 20.7 & 19.0 \\
\hline DKC 9042 (V5) & 5.3 & 7.3 & 10.7 & 20.1 & 30.9 & 31.3 & 33.8 & 35.1 & 36.5 & 37.8 & 35.8 & 31.1 & 21.4 & 18.2 \\
\hline Pinnacle (V6) & 7.0 & 8.1 & 11.7 & 22.0 & 32.0 & 33.5 & 35.8 & 36.3 & 37.6 & 40.0 & 37.1 & 32.1 & 22.5 & 19.2 \\
\hline SEm \pm & 0.45 & 0.38 & 0.45 & 0.82 & 0.45 & 0.41 & 0.70 & 0.47 & 0.45 & 1.06 & 0.78 & 0.49 & 0.90 & 0.66 \\
\hline CV\% & 10.50 & 7.12 & 5.67 & 5.49 & 5.05 & $7 \mathrm{~S} .80$ & 2.88 & 1.86 & 1.73 & 3.84 & 3.00 & 2.20 & 5.82 & 5.00 \\
\hline$C D(p=0.05)$ & 0.967 & NS & NS & 1.76 & 0.96 & 0.88 & 1.51 & 1.00 & 0.97 & NS & NS & 1.06 & 1.92 & NS \\
\hline
\end{tabular}


Fig.1 Number of leaves in maize hybrids duringrabi 2016-17

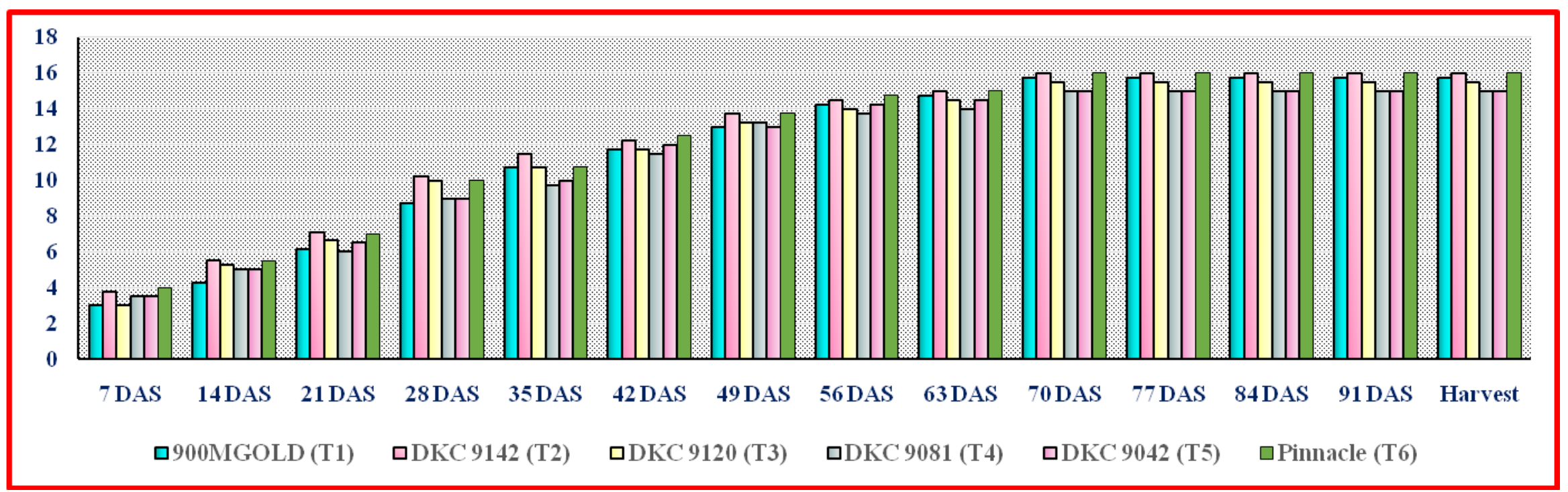

Fig.2 Net photosynthetic rate of maize hybrids during rabi 2016- 17

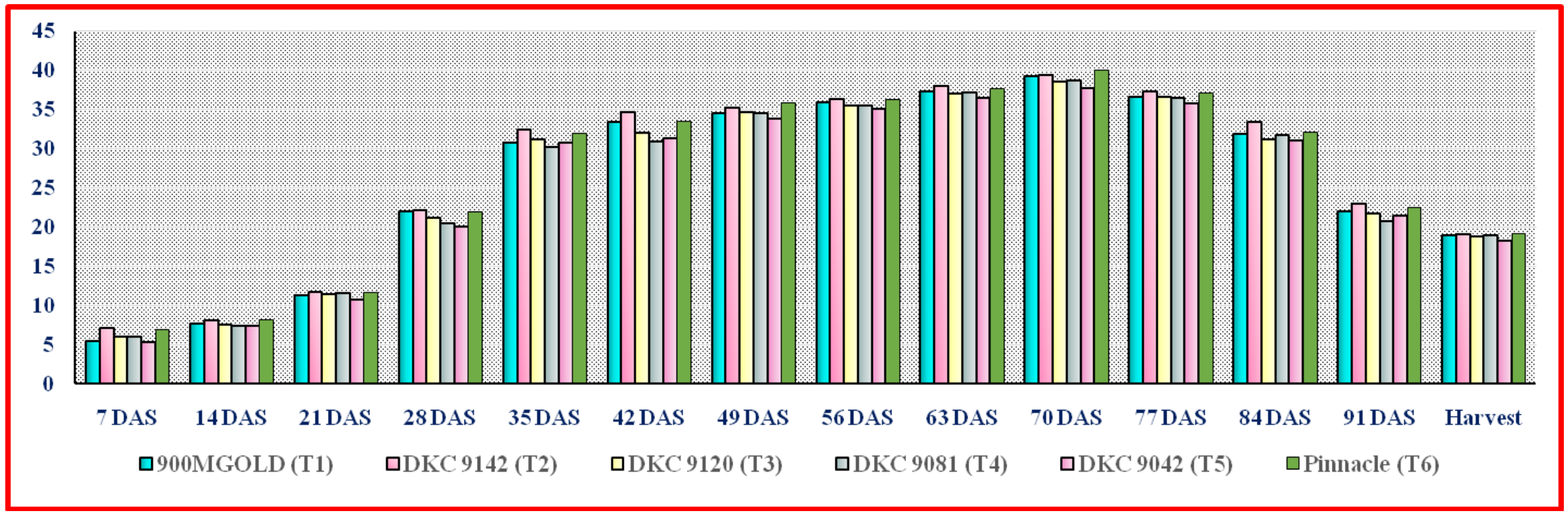


Among the maize hybrids, at 42DAS the stages vary among different hybrids based on number of leaves expanded; pinnacle (V1212.50), DKC9142 (V12-12.25), DKC 9042 (V12-12.00), 900MGold (V11-11.75) and DKC 9081 (V11-11.50) (Forsthofer et al., 2004). The rate of leaf appearance ultimately depends on the initiation of leaf primordial until the phase shifting from vegetative primordial transition to reproductive stage, i.e; initiation of tassel and cob primordial differentiation in maize (Ne Smith and Ritchie, 1992). The time elapsing between sowing and silking is associated with the number of leaves per plant and the rate of leaf appearance (Tollenaar et al., 1979). From the reduction in increasing leaf number, it is evident that the silking date implies a reduction in plant size as per the results.

Net Photosynthetic rate $\left(P_{n}\right)\left(\mu\right.$ mol $\mathrm{CO}_{2} \mathrm{~m}^{-2}$ $\mathrm{S}^{-1}$ )

At 7DAS, DKC 9142 and Pinnacle (7.0) recorded significantly later, higher photosynthetic rate and at 14 and 21DAS the variation was non-significant. Later a sharp increase was noticed at 28DAS, DKC 9142 (22.10), Pinnacle(21.89) and 900M Gold recorded significantly higher photosynthetic rates than other three and same trend was noticed at 35 DAS with Pn values ranged from 30.85 to 32.50 . At $42 \mathrm{DAS}$, another maize hybrid 900Mgold (33.50) also recorded significantly higher value along with DKC 9142(34.63) and Pinnacle (32.03) than other three. At 49 DAS, Pn in Pinnacle was found high over only one hybrid DKC 9042. Later at 56 DAS and 63 DAS, both DKC 9142 and Pinnacle had the $\mathrm{P}_{\mathrm{n}}$ higher than DKC 9042, but on par with others. The maximum net photosynthetic rate was recorded in all maize at 70DAS ranging from 37.80 to 39.95 but all hybrids are at a par. From 77DAS reduction in net photosynthetic rate was observed and declining trend was continued as the age of the crop reaching towards the physiological maturity. During this declining stage also, DKC 9142 and Pinnacle exhibited relatively high $\mathrm{P}_{\mathrm{n}}$.

The lower photosynthetic rates are the result of increasing the resistance of the mesophyll cells to the passage of $\mathrm{CO}_{2}$ (or intracellular resistance), reflecting changes in the enzymatic apparatus, leaf anatomy and structure of chloroplasts (Patakas et al., 2003). The structure of a canopy culture is important because it modulates the surrounding microenvironment, including the radiant flux density, temperature of the air and soil and also vapor pressure of the air, temperature of the leaves, accumulation of heat in the soil and wind speed (Nobel et al., 1993). Therefore, the plants in communities are interdependent (Irmak et al., 2008). Even with regard to biological invasions, the adaptability of a species depends on the environment, particularly the light and nutrient availability, and such plant physiological characteristics as $\mathrm{C}_{3}$ or $\mathrm{C}_{4}$ metabolism (Funk and Vitousek, 2007).

As crop age advances the change in crop phenology and its leaf appearance was positively correlated along with its net photosynthetic rate during grand growth stage that indicates the peak vegetative and initiation of reproductive phenological stages of maize crop. However, the progress of phenological stages of maize crop depends on environmental and edaphic factors.

\section{References}

Bavec, F. and Bavec, M. 2002. Effects of plant population on leaf area index, cob characteristics and grain yield of early maturing maize cultivars (FAO 100400). European Journal of Agronomy, 16, Pp.151-159.

Forsthofer,E.LSila $\quad$ P.R.P $\quad$ Strider,M.L 
Suhre,E.Rambo,L.2004.

Maize development Cinicia rural V 34 :Pp 1341-1348.

Funk, J.L. Vitousek, P. M. 2007. Resource-use efficiency and plant invasion in lowresource systems. Nature, v. 4, n. 9, Pp. 1079-1081.

Montpied, P. Granier, A. Dreyer, E. 2009. Seasonal time-course of gradients of photosynthetic capacity and mesophyll conductance to $\mathrm{CO} 2$ across a beech (Fagussylvatica L.) canopy. Journal of Experimental Botany, v. 60, n. 8, Pp. 2407-241.

NeSmith D.S, Ritchie J.T. 1992. Short- and long-term responses of corn to preanthesis soil water deficit. Agronomy Journal 84: 107-113

Nobel, P. Forseth, I. N, Long, S. P.1993. Canopy structure and light interception. In: Hall, D.London, Chapman and Hall. Pp. 79-90.
Panse, M and Sukhatme,K.1978. Statistical methods for agricultural workers.Indian Council of Agricultural Research Publication.Pp 58-67.

Patakas, A.Kofidis, G. Bosabalidis A. M. 2003. The relationships between $\mathrm{CO} 2$ transfer mesophyll resistance and photosynthetic efficiency in grapevine cultivars. ScientiaHorticulturae, v. 97, n. 3, p. 255-263.

Streck,N.A

Gabriel,L.F,Samboranha,F,K.Lago,I.20 09. Comparing two variations of nonlinear model for simulating leaf number and developmental stages in maize based on air temperature Cienica Rural, V39: Pp 642-648.

Tollenaar M, Daynard TB, Hunter RB. 1979. Effect of temperature on rate of leaf appearance and flowering date in maize. Crop Science 19: 363-366.

\section{How to cite this article:}

Ravi Babu, M., K. L. Narasimharao, Y. Ashoka Rani, M. Martinluther and Prasad, P. R. K. 2019. Determination of Crop Phenological Phase Based on Leaf Number and Net Photosynthetic Rate in Six Maize (zea mays l.) Hybrids. Int.J.Curr.Microbiol.App.Sci. 8(09): 2887- 2893. doi: https://doi.org/10.20546/ijcmas.2019.809.332 